\title{
Parasitical Paintings
}

\begin{abstract}
This article will explore three parasitical terms - mooch, commensal and mutualistas models that can be applied to recent instances of contemporary painting practices that use historical painting as a catalyst for new works. There will be a brief introduction to the terminology of the parasite, the conceptual position of the parasitical painter and to Michel Serres' notion of the parasite. The research is driven by the perspective of the author's painting practice, which will be discussed, alongside an analysis of Pavel Büchler, Yelena Popova and Hans-Peter Feldmann's work, in relation to different types of parasitical painting practices. Artists such as those explored in this text have reached beyond established notions of appropriation to use existing paintings as primary material in their work. The act of doing something to existing paintings opens up questions over value, re-imag(in)ing, distortion, re-use, rejuvenation, re-evaluation and originality, among many others. The article closes with speculations for future investigation; through notions of interrupting the interrupter and the switching of roles form the influenced to the influencer.
\end{abstract}

- Keywords - painting, parasite, host, commensal, mutualist, mooch, appropriation

\section{Parasitical Paintings}

\section{Andrew Bracey}

\section{To drag a parasite out into the light}

'When we drag a parasite out into the light and examine it from every angle medical, cultural, historical, environmental and emotional - we find that it has as many faces as a clown in a house of mirrors' (Drisdelle 2010: 125).

The biological parasite summons thoughts related to human or animal suffering, though as Drisdelle's quote suggests the reality is far more complex. A parasite is defined by its actions, as opposed to being set by classification; actions upon a host 
that they live within or on and which provides what they need to survive. Parasites, such as the common microscopic intestinal parasite, Giardia or Pediculus humanus capitis, the head louse, are pervasive and omnipresent, with the human body being host to numerous near-invisible parasitical creatures, and likewise for almost every species of animal and countless plants. Despite their widespread presence among us, the consensus is that the parasite is a contemptible creature that causes damage and harm to its host and society. Examined closely they are confirmed as a triumph of the Darwinian need to adapt and survive.

The earliest derivation of the word parasite is the Ancient Greek, parasitos that described humans who lived at the expense of others. The similar Latin term, parasitus, referred to a sponger or toady. The biological or medical meaning has overtaken this reference to human behaviour in common usage in recent centuries. Clinical parasitologist, Rosemary Drisdelle, describes the parasitical through the word mooch, referring to the manipulative friend who always arrives exactly at dinnertime, going on to say, 'We can easily see why the creatures that live in us and on us have acquired the same label: they flourish at our expense' (Drisdelle 2011: 36). The emphasis on prospering at the cost to the host is a significant one and perhaps goes some way to explain the negative connotations of the parasite. Parasites (mooches) are understood to only take from the host without giving anything in return, be it food, blood or life, This understanding is perpetuated by common perception and disgust associated with imagery and learnt behaviour caused by the worst aspects of the parasite.

The symbiont is a sub-class of the parasite that inhabits, but crucially does not cause harm to the host. For example the Siboglinid tubeworm has no digestive ability and has to rely on symbiotic-bacteria to oxidise the gases ingested by the worm to provide it with nutrition. Within parasitology, there are two general classifications for symbiosis. Commensal describes a group whose activities lead to benefit for the parasite, but none for the host. If the relationship is built on interdependence, and benefit can be seen in both parties, then the bond is said to be mutualist (Young 2016: 35). The term, mutualist has been widely adopted in many circumstances away from biology in reference to mutual cooperation, particularly within economics (Travers- 
Borgstroem 1921), using theories expounded by the anarchist, Pierre-Joseph Proudhorn.

In his seminal book, The Parasite, Michel Serres pulled together the fields of humanities, arts and the sciences to explore and go beyond Marcel Mauss' concept of the gift. Serres suggested that rather than looking at distinctions, it is the relationship between different parties that is integral to the understanding of knowledge; the parasite is put forward as a revised model for cultural and social interactions. Serres replaces the gift and its obligation of debt with exploitative exchange based on abuse value (Serres 2007: 80). Serres' position of the parasite is extended to notions of the guest and of noise, rooted in notions of exchange, is predicated towards negative associations of the parasite. This article will fold Serres' reading of the parasite with the application of the three scientific terms (mooch, commensal and mutualist) introduced above to provide insight (through analogy) into the practice of contemporary painters.

There is a long history of artists incorporating other artist's methods and imagery. This could be seen to have led to tendencies over the last hundred years of artists channelling a relationship with Old Masters in an attempt to inhabit their work, akin to a mooch's infiltration of a host. Tony Godfrey has noted that Phillip Guston, 'like many other painters, in times of stress or uncertainties turned to the Old Masters' (Godfrey 2009: 47). Stress and uncertainty can be common to a parasitical relationship, but can become something that enables the parasitical artist to generate something incredibly productive. For example, Francis Bacon painted forty-five versions of Velásquez's Pope Innocent X, known as the Screaming Popes (fig 1). In this case it appears that the re-working raised issues of Bacon's self-questioning, or as Deleuze has interpreted 'doubt or discontent' (Deleuze 2005: 38), akin to the anxiety, feasibly, caused to a host by a parasite's presence. We can interpret examples such as the Screaming Popes as questioning the harm a parasitical painter such as Bacon is doing, or has done to the host painters/paintings. I would say that this is emblematic of the relationship many twentieth century painters had with past master painters and paintings. A more generous reading is that the new readings of previous artists' work, such as Bacon's versions of Velásquez's Pope, allow a mutualist relationship to meaning; though there is ambiguity as to which artist gains what and who gains most. 
More recently, painters including Andrew Grassie, Henrietta Simson, Genieve Figgis and Ian Kiaer have used other artist's paintings as subject matter and imagery in their work. Artists such as these use existing paintings to reach beyond established notions of appropriation. The act of doing something to existing paintings opens up questions over value, re-imag(in)ing, distortion, re-use, rejuvenation, re-evaluation and originality. The article will consider whether painters adopting a stance of beneficial parasitism (Leopoulou 2016) can be applied to painting, in a manner already established in relation to socially engaged practices (Leopoulou 2016; Post Brothers \& Fitzpatrick 2011).

Glenn Brown stretches, compresses and exaggerates works by painters, such as Fragonard, Velásquez and Rembrandt. A process of amplification and subversion of colour, composition and details of reproduced paintings creates his original and distinctive works, such as in The Day the World Turned Auerbach (fig 2). Brown, as a parasitical influence revels in the paradoxical nature of his work; his 'too-glossy facsimile' (Falconer 2015: 354) paintings are representations of representations of existing artworks that 'are appropriations that are not appropriations, transcriptions that are much more than transcriptions' (Vouden \& Freedberg 2009: 112).

Some artists have taken the idea of inhabiting a painting further by incorporating other artists' actual works in and as their own, to create layers of authorship, meaning and layered readings. For example, a genteel painting is transformed through Asger Jorn's invasive painted additions in his Modifications series (1959-1968); a triangular relationship is created between iconic paintings and specifically selected objects in over 500 examples of Braco Dimitrijević installation series, Triptychos Post Historicus (1978 - today); , and a Gerhard Richter Grau painting becomes a coffee table top in the hands of Martin Kippenberger in Modell Interconti, 1987.

\section{Four Painters Parasitically Reimagined}

Yelena Popova produces subtle, minimal paintings that appear to present a trace or echo of something, akin to the ripple effect of the after-shocks of an earthquake still affecting somewhere far from the epicentre. Her painted marks, only barely perceivable on the raw linen, are worthy of greater attention. Popova's work is cited as evoking 20th-century art movements associated with abstraction, such as 
Minimalism, Constructivism and Futurism; something acknowledged by the artist. In recent years Popova's work has increasingly had its roots in portraiture. Her solo exhibition at Nottingham Contemporary in 2016 featured a suite of perhaps her most invisible pieces, giving a sense of the pigment being 'hardly there, a spiralling wash that spectrally recalls Old Master portraits and Renaissance virgins' (Dillon 2016: 17). Public Paintings inhabit a near-invisible status, akin to the parasite, that is agitated through Popova's use of thinned down paint. Serres' talks of the parasite as the most silent of beings; 'it is invisible, it cannot be felt; it copies so as to disappear...it keeps quiet; it listens. It observes' (Serres 2007: 237). I would extend this reading of silence of the parasite to the painter's ability to subtly allow themselves to infiltrate other artist's work. Often this is near invisible or not readily felt and yet allows the painter to observe and (to paraphrase Serres) to trouble established reading of paintings, without being troubled (Serres 2007: 238) by it.

The invisibility of the parasite is a vital one. It allows us to pretend that they are not present within our bodies and those around us. It is easy to forget the impact of parasites on human history, they are not present in history books (Drisdelle 2011: 2) and yet their actions have had a huge impact on the earth's ecosystem and human affairs. It is helpful to segregate the sentient being, the parasite, from the noun, parasitism, which 'invokes a more positive state used to describe a common biological function based on coexistence' (Leopoulou 2016).

Popova's marks are active, just as the parasites are in our bodies, but they need to be almost forensically paid attention to, after all 'in a host's home, a parasite must be humble and quiet' (Post Brothers \& Fitzpatrick 2011). This artistic form of parasitism is analogous to the relationship of the Hawaiian bobtail squid and the lustrous bacterium, Vibrio Fischeri (McFall-Ngai 2014). In daylight, the squid's natural colour is camouflaged to the seabed. At night the squid emits ventral luminescence to camouflage its underside against the light of the stars and moon. However this kaleidoscope of colour is actually the presence of a landscape created by Vibrio Fischeri, which is 'like the protagonists of science fiction stories, who terraform inhospitable planets into comfortable homes - except it terraforms an animal' (Young 2016: 52-53). 
I would venture that there is commonality between parasites such as Vibrio Fischeri in relation to their host squid and Popova's relationship to portrait painting. They both terraform their respective hosts without harm. Their visual distinction creates a place where the parasite transforms the host positively and without its presence really being taken into account they, Popova and the microbe, both sculpt the body of the painting or the squid with their own presence, to take on the position of the subject, without making more noise than is necessary.

'The observer makes less noise than the observed. He is thus unobservable by the observed. That is why he troubles and is not troubled, that is why he is an asymmetric operator. He supplants by essence and by function. He is in the position of the subject' (Serres 2007: 238).

Serres' idea of the parasite as a hushed observer is applicable here. Popova has stated in email correspondence that "I perceive myself neither as parasite nor a symbiont" in her artistic relationship to historical paintings. I would argue however that Popova is in a commensal relationship to the paintings and painters she uses as starting points for her work; acting as the observer making less noise than the observed, but having a profound effect. She sees her dialogue with historical paintings as comparable to the relationship that "a contemporary philosophy scholar has to Greek (or any other historic) philosophy. They are a foundation, the history of the medium, the depository of the non verbal knowledge". Popova's distinctive drawings on top of postcards of Renaissance and Tudor portraits reveal glimpses of the original below the milky whiteness of Popova's marks sitting on the surface. Echoes of these compositions are seen in her linen paintings produced for her 2014 solo exhibition, The Portrait Gallery Withdrawn at Eastside Projects in Birmingham (fig 3). These works I believe are her most cogent and urgent paintings, where her marks almost consume and take over a host image. John Slyce has remarked that there is a 'withdrawal from the painted image in these works, which render only a vestige or ghostly shadow in an installation where light is the agent in revealing the absence of a face' (Melick 2016: 252). The near-invisibility of the original image by the neartransparent additional marks may be nuanced and subtle, but a key facet is how, or perhaps why, the existing work by another artist remains present in Popova's paintings. 
Pavel Büchler's Modern Paintings (fig 4) begin with rooting through charity shops and vacated post-degree art college studios to find abandoned paintings. Unlike Popova's work, the original paintings he uses are not ones to be held up as ones of artistic significance; as the artist said in a studio visit, "They have to be failed paintings and also modern paintings, not Monarch of the Glen type, but more the evening school amateur attempting Cezanne”. Büchler applies multiple layers of primer to obliterate the original painting, before pulling the fragments of paint off the canvas. Modern Paintings are created by then sticking the primer side of the fragments to the machine-washed canvas to reveal a new hybrid composition, formed from the washed canvas and fragments of the back of the original painting. The work, which recalls crazy paving, thus contains the material of the original painting, but with minimal reference to the work of the original artist's creative output.

Büchler's parasitical use of existing works of art is in line with the popular understanding of the parasite, the mooch. Büchler uses other artists' work for his own purposes, not to create a symbiotic dialogue with them, but to create a new work from the host by disfiguring and nearly destroying the original painting in the process, something distinct from my own use of existing works in ReconFigure paintings discussed later. This process could have its seeds in the biological phenomenon biofouling where microorganisms, plants or animals accumulate to cover a wetted surface, such as how the tubular worm, Hydroides Elegans, takes over the hull of ships (Young 2016: 59). In the case of Büchler's work, the artist uses the material that was already present in the host, but not the content.

Büchler's presence is not invisible, as we like to think of parasites, but instead highly visible, the harm he causes to the original is visible for all to see. However this harm is instilled with a strong sense of value and of renewal. It could be speculated that every painting rescued from the skip by the artist, donated by friends or bought at auction gained artistic (or rather conceptual) credibility by Büchler's actions. This position is maintained because of the provisional status of the original; if Büchler were to use a known or artistically valued painting, as in work by the Chapman Brothers or Asger Jorn, then the artist's act would be seen differently. The parasite can often be inconsistent in their behaviour, as is similarly the case with Modern Paintings; for a 2012 exhibition Büchler created all new works derived from Eddie 
Wolfram's original paintings. The gain of Büchler's parasitical activity depends upon the host that is chosen, as Joan Key states 'this literal re-covering of the failed painting courts the possible failure of the painting that results' (Key 2007: 124). Modern Paintings rely on the presumed failure of the original painting to have any chance of their own success, instilling a sense that the 'rigorously linear direction of Büchler's painterly process is strictly one way' (Ibid). This one-way direction is implicit for the success of the work; it implies that the viewer has no knowledge of the host artist's paintings, in order to allow the work of Büchler to dominate. A trace of the original is left in the subtitle of each piece - Modern Paintings No. A39 (crouching male figure in brightly lit window, Manchester, July 2000) or Modern Paintings No. A33 (black, red and white chess board pattern with green stripe, Manchester, June 1999). The words of the titles factually describe the image that was once there, as opposed to what the work is now. What we see are lost and failed paintings re-valued by Büchler's conceptual approach, which almost as a by-product creates genuinely engaging paintings, something that can channel feelings of a 'guilty' reception (Crowe 2004: 38) in light of the artist's oeuvre.

Hans-Peter Feldmann has an intoxicating relationship to images in his varied output, producing numerous artist books of collated images and sometimes replacing words with images in reply to interview questions. The artist has said that 'art is a unique form of communication, a unique language. Just as the language of words is a unique form of communication. How should I try to explain the language of art with the language of words?' (Tatay 2012: 221). The parasitical artist becomes intrinsically linked to the language of the host, as a survival strategy. The grapple with dealing with the approach of a purely aesthetic language of art has perhaps drawn Feldmann to the use of existing paintings in recent years after initially stopping painting in 1968 (Evers 2011: 96).

The installation, Untitled (Seascapes), consists of 15 canvases that adopt the salon hang to evoke a different, more classical era (fig 5). The artist removed everything, including boats, people and landmarks that were neither sea nor sky to universalise the paintings. The main event or narrative is removed in Feldmann's hands to liberate the paintings from spectacle and become a more accurate representation of what the sea is. As Dirk Lucklow states, this removal of the key narrative is 'consistent with 
his fundamental approach of bringing our attention not to the five minutes of the day that were interesting, but to all the other minutes, which comprise normal life' (Tatay 2012: 259).

Feldmann does create spectacle through adjusted canvas paintings, that teasingly add elements such as anarchic clown noses, crossed or black eyes to portraits in a witty or arguably redundant (Searle 2012) update on Duchamp's L.H.O.O.Q. The adjusted paintings are a mix of unfamiliar originals and copies of iconic paintings; for example, he has added tan lines to Courbet's L'Origine du monde and Titian's Venus of Urbino. Perhaps more powerful are the paintings where eyes, breasts and genitals have been covered with blackout bars, conjuring absurdity to a Western gallery-going public, whilst also teasing out more affecting, persistent issues around censorship of imagery and of human rights (fig 6).

The approach of Feldmann in relation to existing paintings is clearly parasitic: he is using the original authority of the image and his subtle, as seen in Untitled (Seascapes), and not-so-subtle interventions affects a change in our relationship to the host/original painting. It could be argued that Feldmann is a mooch, using and taking over the original, however there is also a dialogue that is occurring between generations that, to my mind, is more akin to a mutualist relationship. Harm is done to the original canvases in a physical way, though often the works are copies of original paintings, but experientially and conceptually the actions of Feldmann are adding to the experience of the original painting. There is a gain for both parties by contemporising issues that were not initially present, but are brought out in the original painting by the artist's interventions. Perhaps the generosity of the parasitical stance is given more credence by the artist's position on democratic views towards authorship and ownership; he does not sign his works, for example. The artist believes works of art to be common property and has said that 'if I bought a Van Gogh, it wouldn't be mine. It belongs to everyone...The canvas and the paint aren't important. What counts is the memory: What we project onto a work is what lasts' (Evers 2011: 97). If Feldmann is taken at his word then the memory of the original painting through his altered version is a crucial aspect here. Feldmann uses the original image to create his work and relies on the hospitality of the host to allow something more complex to emerge through our recalling of the original when we are viewing 
Feldmann's, or vice versa the Feldmann when we encounter the Courbet or Titian. In this way the parasite has permeated our consciousness, even if and when we see the clean original painting.

For a parasite to be successful, it must be specialised towards its purpose and able to adapt, often to stay invisible, as the host adjusts and changes in response to the parasite's presence. Serres identifies how metamorphosis can make the parasite disappear, simultaneously being and not-being there. If the parasite is unable to adapt then they can be overcome or exterminated by their host (Gullestad 2012). The visibility, or adoption, of the parasitical gesture is something I am acutely aware of in my recent work. In Transitory Paintings reproductions of paintings are sourced from auction catalogues. As the artworks pass from one private owner to another private owner, the general public only sees them for a brief moment at the time of the auction and hence it is the auction catalogue that becomes the public record. Triangles are cut from reproduced paintings to create an abstract skeletal structure, whilst conserving fragments of the figurative original. The cut could be read as a violent gesture, but I maintain it is something that opens up a conversation around painting, authorship and hiddenness. This position is analogous with the parasite being part of a balanced world. My work does not harm the original paintings, as they are reproductions, but instead seeks to open up discussion about paintings that are absent from public view. The parasitical gesture of the cut and partial removal of the image makes visible a painting forgotten in the visual imaginary, one gathering dust in the auction house catalogue. It is visible anew, because of the parasitical gesture.

Nicolas Bourriaud has discussed the idea of artists inserting their work into others to 'contribute to the eradication of the traditional distinction between production and consumption, creation and copy, readymade and original work. The material they manipulate is no longer primary' (Bourriaud 2005: 13). By contrast, the parasitical gesture takes an image with inherent cultural value to use as primary material, akin to charcoal, stone or paint. By repositioning the completed cultural object as primary material, the contemporary artist is metaphorically and materially operating as a parasite and this is certainly true of my own position in the use of this material. In some cases 'appropriated material no longer need signify anything in particular; not the death of the author, not a critique of mass-media representations, not a comment 
on consumer capitalism' (Soutter [2006] 2009: 166). The incorporation of historically important paintings as material has allowed my work to enter directly into a productive conversation with, and critique of, the painting discipline. This is specifically related to the dominance of the figure in art historical interpretations, where most readings concentrate on the person above other details relating to background and assembled objects. Serres reminds us that humans are the parasite of all parasites; we take (Serres 2007: 5) but rarely give back, and usually cause death to species around us.

The individuals in historical paintings are replaced with triangular structures in my ReconFigure Paintings (fig 7). Attention is diverted from the known figure towards a sense of not-knowing (Fisher \& Fortnum: 2013) by this painterly tactic and alternative ways of looking become possible. Other parts of the reproduced painting summon possibilities for what or who might be below the geometric cocoons in the mind of the viewer; whilst also creating a tension between the original and reproduction, the representational and the abstract. Painted marks are responsive to the original painting, particularly in regards to a conceptual approach to colour (Wainwright \& Bracey: 2014). The colour is sometimes derived from the removed figures or harmonious with other parts of the painting and sometimes it is completely alien or other to it. The decision-making is comparable to Jorn's Modifications where 'he makes his additions to the edges of the central motifs, and applies them in such a fashion that they seem to rival the motifs in the existing painting, to cancel them out with something equivalent but incoherent' (Falconer 2015: 256). I understand Jorn's additional painted marks as offering new potentials to the original painting, which rather than making meaning 'bleed from the pictures' (ibid), instead creates a space where meaning pours into the painting. The process of adaptation of a painting's surface and content is not so different from the parasite's specialist adaptation to the host; to be able to be present, but not overpowered by the original painting. A complex relationship is created with the host paintings, where the new painted marks have to be visible enough to invoke these possible responses, but to leave enough of the original painting so they create fresh ways of seeing it; to be both friend and stranger to the host. 
The parasitical relationship was further complicated with a commission to create a new series of ReconFigure Paintings with original paintings from the Madsen bequest to York Art Gallery for the exhibition Finding The Value in 2014. In this case the host paintings were unique, meaning that my additions created a sense of extinction in and for the host, but also a transformative or evolutionary shift in the original. The difference between using the original paintings and reproductions was significant for the conceptual approaches behind the work, though the studio process was aesthetically no different. My parasitical position is one driven by empathy with the host, one where I imagine that the roles of parasite and host could theoretically be within a state of 'constantly reversing relations' (Post Brothers \& Fitzpatrick 2011), where there is mutual gain through the intimate yet poisonous interaction between parasite and host provides a more nuanced way of charting exploitation between parties' (Ibid). This becomes an ideal to work towards, whilst also being mindful of the distinctions of mooch, commensal and mutualist in my own work and that of other's work where I see parasitical tendencies in existing paintings.

\section{Parasitical Hosting}

Robert Rauschenberg's Erased de Kooning drawing (fig 8) is a pivotal work in regard to the position of the parasitical artist. The status of the original source, coupled with the purging (Kotz 2004: 82) action of Rauschenberg's removal of the Abstract Expressionist Willem De Kooning's (Foster, Krauss, Bois, Buchloch, Joselit, 2011: 406) marks critically plays with authorship in relation to the value and power of the artist. As Jennifer Mundy acknowledges, 'part of the appeal of Rauschenberg's work was of course the mystery surrounding the lost drawing by de Kooning: after all, not knowing is a powerful inducement to attempt to know' (Mundy 2013: 178).

Somewhat less known is the contribution of a third artist to the work; the integral gold frame and the inscription in the mounting board, Erased de Kooning Drawing, Robert Rauschenberg, 1953, were both contributed by Jasper Johns (Roberts 2013).

Rauschenberg is passing on a parasitical mantle on to Johns, whilst also hosting the work of this other artist in his own work. As a work of art it relies on the work of the host and the parasite(s). The implication of work in this case allows the artefact to be kept active, to be kept in a state of doing. 
Rauschenberg, I would argue, fits all three classifications of parasite (mooch, commensal and mutualist) whilst also being a host, precisely because the complexity of his practice is kept active and is resourceful. He extends beyond the parasite to become, what I would term, welcoming-host, comparable in approach to the Californian Tarweed. This resilient plant is seen by many to be a pest, a parasite on the landscape. However the qualities that make this plant unwelcome, such as being hard to get rid of, also make it a vital to many other life forms, such as butterflies, predatory insects, and birds, especially when other plants have died in the harsh landscape. Bees use the sticky excretions of the tarweed to bolster their hives from predators and parasites. Rauschenberg comparably uses other artists' works, ideas and materials, whilst also playing host and working with others interchangeably, as seen in his work with E.A.T., or the choreographer Merce Cunningham. Short Circuit is an early, collaged Combine that the artist submitted to the annual exhibition at Stable Gallery in 1955. After their rejection to the same exhibition, paintings by Jasper Johns and Susan Well were smuggled into the exhibition by being placed under doors and incorporated into Short Circuit. In a further twist, Jasper John's painting went missing a decade later and the host, Rauschenberg, consequently invited Elaine Sturtevant to replace Johns' work with an exact replica. The shifting focus of Rauschenberg's status in relationto the parasite and host is reflective of the nature and personality of this particular artist, who was inclined towards different forms of collaborative relationships and outputs. However there is a further extrapolation of the shift in attention from stance of the parasitical towards that of becoming equally the welcoming host, through the stance of how we interpret influence.

The position of a two-way interpretation allows for the most potent reasoning for artists' use of the imagery of existing paintings. The contemporary artists discussed are all creating a contemptuous dialogue with the host paintings through their artwork. The additions, and/or subtractions, by the contemporary artist to the existing artwork create a space where both versions can be conjured concurrently in a relationship that can be many things, provocative, turgid, harmonious, political, aesthetic and so on. As we have seen in the examples above, the relationship the contemporary artist has with the existing paintings adds something that was not there before, often through an interruption, after all the parasite is an interrupter (Serres 2007: 111). The position of 
the parasite is akin to an 'optical device with which to see relations break down' (Post Brothers \& Fitzpatrick 2011) that also through the artist working parasitically with other artists' work, makes these relations visible. Whether the effect is of benefit or otherwise to the original painting is in the perception and subjective stance of the parasitical artist, the host artwork and the viewer.

Changes made to the original paintings by Feldmann, Büchler and myself are clearly visible in the abuse value (Serres 2007: 80) in connection to the host and are paradoxically also hiding in plain sight. Serres' analysis of the politician as a parasite occupying the dual position of being and nonbeing is helpful in this regard; 'nothing exists more than he does since he is always there in our relations and in the systems in which we live, but nothing exists less than he does since a certain noise makes him immediately disappear. He is the noise of a system that can only be supplanted by noise' (Serres 2007: 79). Supplanting the noise of the host with the idea of noise of the parasite can relate to the quotation or appropriation of material by a painter, as a violent act. The harm caused does not have to be visible; it can be made to disappear by the contemporary artist and is correlated to the parasite harming the host, such as the guinea worm, Dracunculus, or toxoplasma. The harm caused to the original work of art may not be as extreme as that caused by the biological parasites to their hosts, however it can be multifarious, prompting questions around whom or what is the harm that is done. The Chapman Brothers could be said to have done physical harm to the edition of Goya's Disasters of War etchings, however it is much more ambiguous if this has caused harm to their, or indeed Goya's cultural legacy? In the case of Feldmann, and I would venture, in my own work, the host is gaining from the presence of the parasite; as Serres ventures the host needs the parasite as our bodies need bacteria to rejuvenate and revive (Serres 2007: 34). I would argue that when an artist is genuine in their enquiry, without being deferential to the host, then the subterfuge of becoming invisible (Popova, Rauschenberg) or of 'taking on' the original painter (Bacon, Büchler, Feldmann) is to be interpreted as healthy.

Serres' posture of whether the host can interrupt the interrupter leads to an extension of this logic; a question of 'would the best hosts be the best parasites?' (ibid) It is worth taking this into account when considering the artists outlined above of whether their practices could allow the possibility of the original artists reversing their roles. 
This is certainly conceivable as a theoretical idea, and one readily pushed into the reception and interpretation of the artworks. Time, circumstance and the status of a position can change the perception of whether the parasitical status of the artist using existing artworks is that of mooch, commensal, mutualist or even the welcoming-host.

It is useful here to return to the issue of influence. A common interpretation is that the influence is chronological, we look back to locate influence. However just as the position of the parasite can shift through perceptual positioning to even consume and include the parallel role of the host, so influence can become more complex than traditionally thought. Michael Baxendall proposes a position where the influenced (X) becomes the influencer ( $\mathrm{Y})$, as it is $\mathrm{Y}$ that is actually doing something because they are active and is seemingly changing views and positions of $\mathrm{X}$ through the evaluation. As Baxendall states, 'To say that $\mathrm{X}$ is influenced by $\mathrm{Y}$ is to beg the question of cause without quite appearing to do so. After all if $\mathrm{X}$ is the sort of fact that $\mathrm{X}$ acts on people, there seems no pressing need to ask why $\mathrm{Y}$ was acted upon: the implication is that $\mathrm{X}$ simply is that kind of fact - influential' (Baxendall 1989: 59). This allows a more multifaceted and rational reading to do with the work that art is doing. The position of the parasite and the host is interchangeable; this locus occupied by Rauschenberg is exemplary in this regard and aspirational for my own practice. This is in line with biological equivalents where roles by the parasites within the same host can change. I would venture that this interchangeable relationship is at the heart of how the contemporary artist can be the beneficial parasite to the original paintings and the discipline at large, as a material and conceptual host. As Ed Young states, 'these terms are more like states of being, like hungry or awake or alive, or behaviours like cooperating or fighting. They're adjectives and verbs rather than nouns: they describe how two partners relate to one another at a given time and place' (Young 2016: 80).

This state of mind towards the terms Young talks when related to a parasitical relationship of the artist is useful; it puts it into an active state of doing. The parasitical nature of the artist must be kept in a state of change and adaptation, so as to not be consumed or overwhelmed by the host or the weight of painting's history.

\section{References}

Baxendall, M. (1989), Patterns of Intention: On the Historical Explanation of Pictures, London, Yale University Press. 
Bourriaud, N. (2005), Postproduction, New York, Lukas \& Sterberg.

Crowe, N. (2004), Pavel Büchler, in Art Monthly, 279, p37-38.

Deleuze, G. (2005), Francis Bacon, London, Continium.

Dillon, B. (2016) 'A Hazy Grey Sketch of a Limb', in Aristizábal,I and Spinks, A (eds.), Yelena Popova, Nottingham, Nottingham Contemporary, p. 16-19.

Drisdelle, R. (2011), Parasites: Tales Of Humanity's Most Unwelcome Guests, Oakland, University of California Press.

Evers, E. (2011), Picture Euphoria, in Frieze d/e, Winter 2011-12, p. 94-101.

Fisher, E \& Fortnum, R (2013). On Not Knowing: How Artists Think. London: Black Dog Publishing.

Falconer, M. (2015), Painting Beyond Pollock, Phaidon, London.

Foster, H. Krauss, R. Bois, Y. A. Buchloch, B. Joselit, D. (2011) Art Since 1900, London, Thames \& Hudson.

Vouden, R. \& Freedberg, H. (eds.), (2009), Glenn Brown: Three Exhibitions, New York, Rizzoli.

Godfrey, T. (2009), Painting Today, London, Phaidon.

Gullestad A. M. (2012), Parasite, http://www.politicalconcepts.org/issue1/2012parasite/. Accessed 28 November 2016.

Key, J. (2007), Painting as Praxis. In: E. S. Oktern, 2007, Pavel BüchlerAbsentmindedwindowgazing, Rotterdam: Veenman Publishers, p. 121-127.

Kotz, M L. (2004), Rauschenberg, New York, Abrams.

Leopoulou, A (2016), NeMe: Beneficial Parasites, http://www.neme.org/events/beneficial-parasites. Accessed 12 December 2016. 
McFall-Ngai M. (2014). Divining the Essence of Symbiosis: Insights from the SquidVibrio Mode1,

http://journals.plos.org/plosbiology/article?id=10.1371/journal.pbio.1001783.

Accessed 15 January 2017

Mundy, J. (2013), Lost Art, London, Tate.

Popova, Y. (2015), The Collectors Case, Nottingham, Yelena Popova.

Post Brothers \& Fitzpatrick, C. (2011), A Productive Irritant: Parasitical

Inhabitations in Contemporary Art, https://fillip.ca/content/parasitical-inhabitationsin-contemporary-art, Accessed 14 October 2016

Roberts, S. (2013), Erased de Kooning Drawing, https://www.sfmoma.org/artwork/98.298\#essay. Accessed 7 December 2016.

Searle, A. (2012), Hans-Peter Feldmann: Gag Reflex, https://www.theguardian.com/artanddesign/2012/apr/11/hans-peter-feldmann-gagreflex. Accessed 14 January 2017.

Serres, M. (2007), Parasite (Posthumanities), Minneapolis, University of Minnesota Press.

Soutter, L ([2006] 2009), 'The Collapsed Archive: Idris Khan', in Evans, D (ed.), Appropriation, London, Whitechapel Publications, p.166-168.

Tatay, H. (2012), Hans-Peter Feldmann: Catalogue/Katalog, London, Koenig Books. Travers-Borgstroem, A. (1921), Mutualism: A Synthesis, London, MacMillan and Co. Wainwright, H. \& Bracey, A. (2014), Reconfiguring Vision, http://www.nottinghamcastleopen.com/nottingham-castle-open-2015/reconfiguringvision-an-interview-with-andrew-bracey-by-helen-wainwright. Accessed 5th January 2017.

Young, E (2016), I Contain Multitudes: The Microbes Within Us and a Grander View of Life, London, Bodley Head. 
